\title{
Jogo da Minoria: um modelo baseado em agentes aplicado ao mercado financeiro
}

\section{Minority Game: an agent-based model applied to financial market}

\author{
Antonio Fernando Crepaldi ${ }^{1}$ \\ Fernando Fagundes Ferreira ${ }^{2}$ \\ José de Souza Rodrigues ${ }^{1}$
}

\begin{abstract}
Resumo: Nos últimos anos houve uma contribuição significativa dos físicos para a construção de um tipo de modelo baseado em agentes que busca reproduzir, em simulação computacional, o comportamento do mercado financeiro. Esse modelo, chamado Jogo da Minoria consiste de um grupo de agentes que vão ao mercado comprar ou vender ativos. Eles tomam decisões com base em estratégias e, por meio delas, os agentes estabelecem um intrincado jogo de competição e coordenação pela distribuição da riqueza. O modelo tem demonstrado resultados bastante ricos e surpreendentes, tanto na dinâmica do sistema como na capacidade de reproduzir características estatísticas e comportamentais do mercado financeiro. Neste artigo, são apresentadas a estrutura e a dinâmica do Jogo da Minoria, bem como as contribuições recentes relacionadas ao Jogo da Minoria denominado de Grande Canônico, que é um modelo mais bem ajustado às características do mercado financeiro e reproduz as regularidades estatísticas do preço dos ativos chamadas fatos estilizados.
\end{abstract}

Palavras-chave: Modelagem. Simulação. Teoria de jogos. Métodos quantitativos.

\begin{abstract}
Over the past ten years physicists have made a significant contribution to the building of an agent-based model to reproduce the behavior of financial markets using computer simulation. This model, called the Minority Game, consists of a group of agents that buy or sell assets. They make decisions based on strategies, and through them the agents establish an intricate game of competition and coordination resulting in the distribution of wealth. The model has shown outstanding surprising results concerning both the dynamics of the system and the ability to reproduce statistical and behavior characteristics of the financial market. In this study, the structure and dynamics of the Minority Game and the recent contributions related to the Grand Canonical Minority game, a model which is better adapted to the characteristics of the financial market and reproduce the statistical regularities of asset prices (called stylized facts) are presented.
\end{abstract}

Keywords: Modeling. Simulation. Game theory. Quantitative methods.

\section{Introdução}

O mercado financeiro é um elemento-chave no desenvolvimento de uma nação. Por meio dele podem-se financiar projetos de longo prazo que beneficiam empresas e trabalhadores. Apesar de ocupar um papel central no desenvolvimento econômico dos países, também é o palco em que se manifestaram as crises que recentemente levaram muitos países à recessão. Entender os mecanismos que governam a dinâmica do mercado financeiro é um grande desafio. Ainda não se conhece uma teoria ou modelos capazes de prever essas crises ou impedi-las - o que faz deste tema um fascinante tópico de pesquisa e, ao mesmo tempo, um desafio para a ciência moderna.
$\mathrm{O}$ primeiro modelo para o mercado financeiro deve-se a Bachelier em 1900 (SCHACHERMAYER; TEICHMANN, 2008). Esse é basicamente um modelo estocástico que produz séries de preços como um passeio aleatório, cuja função de distribuição do preço é uma Normal. Setenta anos depois, Black e Scholes, beneficiados pelos desenvolvimentos anteriores da teoria de equações diferencias estocásticas, realizados principalmente por Itô (1951), propuseram um modelo parecido, mas a hipótese agora é que o logaritmo do preço é descrito por uma distribuição Normal (BLACK; SHOLES, 1973). Com essa hipótese, eles desenvolveram um método muito utilizado para descrever a evolução do preço de ativos e que

\footnotetext{
${ }^{1}$ Departamento de Engenharia de Produção, Faculdade de Engenharia de Bauru - FEB, Universidade Estadual Paulista - UNESP, Av. Luis Edmundo Carrijo Coube, 1401, CEP 17033-360, Bauru, SP, Brasil, e-mail: crepaldi@feb.unesp.br

${ }^{2}$ Grupo Interdisciplinar de Física da Informação e Economia - GRIFE, Escola de Artes, Ciências e Humanidades - EACH, Universidade de São Paulo - USP, Av. Arlindo Bettio, 1000, CEP 03828-000, São Paulo, SP, Brasil
}

Recebido em 15/3/2010 — Aceito em 3/1/2012

Suporte financeiro: Nenhum. 
permitiu derivar uma expressão para a precificação de derivativos. Embora a hipótese de normalidade esteja incorreta, o método de Black e Scholes é de inegável valor, pois representou um grande avanço para a construção e fundamentação da teoria financeira para mercados futuros.

A grande dificuldade de se obter um modelo mais preciso deve-se ao fato do mercado financeiro ser um sistema complexo formado por muitos agentes que compram ou vendem títulos, ações e outros produtos de forma descentralizada. O comportamento coletivo desses agentes é traduzido em um conjunto de séries temporais de preços que apresentam um padrão de flutuação muito especial chamado de fatos estilizados (CONT, 2001). Estes fatos estilizados são regularidades estatísticas presentes em diversas séries temporais financeiras como: taxas de câmbio, ações, títulos e taxas de juros. Esses resultados são robustos e foram observados em vários países ao longo das últimas décadas. Uma revisão sobre os principais fatos estilizados é realizada no Apêndice A. Essas regularidades estatísticas são, portanto, um fenômeno universal e têm chamado a atenção de físicos e economistas que buscam de forma independente modelos capazes de reproduzi-las. O fato mais intrigante é que a teoria tradicional foi construída com base em hipóteses que não são corroboradas pelos dados empíricos, que aqui chamamos de fatos estilizados. A mais grave violação é a hipótese de normalidade do log-retorno. A presença de caudas pesadas na distribuição dos retornos dos ativos financeiros tem implicações séries. Uma delas é que as grandes flutuações negativas (crashes) deveriam ser eventos muito raros se a teoria estivesse correta, mas, na prática, assistimos a muitos eventos desse tipo nas últimas décadas. Avanços futuros da teoria vigente devem se basear em pressupostos mais realistas. Ela não pode ignorar os dados empíricos e, portanto, precisa levar em conta os fatos estilizados. Contudo é muito difícil encontrar modelos baseados em equações que deem conta de incorporá-los.

Nesse contexto, surge uma nova alternativa, os chamados modelos baseados em agentes. Eles consistem em um conjunto de entidades ou objetos computacionais chamados de agentes, que, por sua vez, interagem entre si de acordo com um conjunto de regras. Ao contrário dos pressupostos da economia neoclássica, os agentes têm racionalidade limitada e são heterogêneos entre si. Eles possuem um conjunto de estratégias que descrevem o seu comportamento individual. Existem vários modelos de agentes para o mercado financeiro (LUX; MARCHESI, 1999; PALMER et al., 1994; LEVY; LEVY; SOLOMON, 1995; BAK; PACZUSKI; SHUBIK, 1997; CALDARELLI; MARSILI; ZHANG, 1997; BROCK; LEBARON, 1996) e este trabalho apresentará e discutirá o Jogo da Minoria e o Jogo da Minoria
Grande Canônico (CHALLET; MARSILI; ZHANG, 2001a, 2005). Esta família ou classe de modelo foi escolhida por possuir poucos parâmetros e produzir séries de retorno do preço com as regularidades estatísticas observadas em séries reais. Portanto, essas evidências empíricas fazem deles modelos competitivos e que podem evoluir para permitir prever as crises (crashes) do mercado financeiro (JOHNSON et al., 2001).

\section{Descrição do modelo do Jogo da Minoria}

Challet e Zhang (1997) propõem o modelo do Jogo da Minoria que busca mimetizar a dinâmica de um mercado de ativos. Inspirado no problema do bar El Farol de Arthur (1994), este modelo baseia-se naqueles investidores que seguem a tendência, ou seja, aqueles responsáveis pelo efeito de manada que levam à formação de bolhas e crashes no mercado. O ponto de partida é pensar que existem dois grupos: compradores e vendedores. Segundo a lei da oferta e demanda, faz um bom negócio quem vender quando a maioria está comprando e vice-versa. Portanto, o melhor é ficar no grupo da minoria. Este mecanismo é apenas uma aproximação, mas pode ser o suficiente para reproduzir ou explicar os dados financeiros.

O chamado Jogo da Minoria consiste em uma população de $\mathbf{N}$ agentes ou jogadores, cada um possuindo um conjunto de $\mathbf{S}$ estratégias que os permitem decidir, a cada jogada e de forma autônoma, comprar ou vender um ativo. Com o decorrer do jogo, obtém-se uma sequência de bits rotulados por 0 e 1 , informando o grupo minoritário, sendo 1 para rotular o grupo de compradores e 0 para os vendedores. Essa sequência recebe o nome de história do jogo.

Cada jogador tem uma memória limitada que o impede de guardar toda a sequência de bits que define a história do jogo. O melhor que ele pode fazer é reter os últimos $\mathrm{m}$ bits da história e, com essa memória, aprender a tomar decisões (comprar ou vender). Esses últimos $\mathrm{m}$ bits representam o estado informacional do sistema no instante te denota-se por $\mu(t)$. A tomada de decisão será orientada por estratégias que levam em conta somente o estado informacional $\mu(\mathrm{t})$. $\mathrm{O}$ conjunto de estratégias, $\mathbf{S}$, de cada agente é fixado no início da simulação e não pode mais ser modificado ao longo da dinâmica. Uma dada estratégia é uma função de $\mu(t)$ que retorna as decisões de comprar ou vender ( 1 e 0 ) o ativo no instante t. Em outras palavras, essa função olha para uma sequência binária $\mu(t)$ e retorna um bit denotado por $\mathrm{a}_{\mathrm{i}, \mathrm{s}} \in\{0,1\}$, representando a ação a ser tomada, em que i representa o agente e s uma de suas estratégias. Um exemplo de estratégia para $\mathbf{m}=3$ é apresentado na Tabela 1 .

Assim, um jogador que tenha como estratégia a Tabela 1 , observa a informação vigente $\mu(t)$ e toma a 
Tabela 1. Possível estratégia para um sinal de tamanho $\mathbf{m}=3$.

\begin{tabular}{cc}
\hline $\boldsymbol{\mu}$ & Ação \\
\hline 000 & 1 \\
001 & 0 \\
010 & 0 \\
011 & 1 \\
100 & 1 \\
101 & 0 \\
110 & 1 \\
111 & 0 \\
\hline
\end{tabular}

decisão segundo a coluna Ação. Por exemplo, quando $\mu(t)=010$, tomará a ação 0 , ou seja, irá vender o ativo.

Existem $2^{\mathrm{m}}$ modos possíveis de configuração (dados de entrada) para uma determinada estratégia e, como cada uma dessas configurações pode apresentar duas ações diferentes, verifica-se que o número de possíveis estratégias é igual a $2^{2^{m}}$. O espaço das estratégias cresce rapidamente com o aumento de $\mathbf{m}$. Para $\mathrm{m}=2,3,4$ o número de estratégias possíveis é 16, 256, 65.536.

Pode-se analisar o jogo sob a ótica de dois extremos. $\mathrm{O}$ primeiro, em que apenas um jogador decide ficar de um lado, por exemplo, no grupo dos compradores, e todos os outros no grupo oposto. Nesse caso, apenas um jogador receberá pontuação. O segundo, em que $\frac{(N-1)}{2}$ jogadores decidem por um grupo e os restantes $\frac{(N+1)}{2}$ por outro grupo. Portanto, $\frac{(N-1)}{2}$ jogadores receberão pontos por pertencerem ao grupo minoritário. Tomando o ganho total como uma medida de desempenho social, nota-se que a ocorrência do segundo caso é preferível e o resultado do jogo flutuará entre esses extremos.

Para iniciar a simulação, um estado $\mu(0)$ é gerado aleatoriamente e também é sorteada, para cada jogador, uma dentre suas $\mathbf{S}$ estratégias, a fim de que tomem suas decisões ( 0 ou 1 ). A cada jogada, todas as $\mathbf{S}$ estratégias, de cada jogador, são avaliadas como vencedoras ou não, levando em conta o estado $\mu(\mathrm{t})$ e o resultado do grupo minoritário da jogada atual. Essa pontuação é feita mesmo para as estratégias que não foram utilizadas na tomada de decisão, portanto, é uma pontuação virtual. Assim, ao longo do jogo, as estratégias vão acumulando pontos segundo sua capacidade preditiva. Porém, somente a estratégia que até aquele instante tenha acumulado o maior número de pontos virtuais será a tomadora de decisão no instante $t+1$.

Ao fim de cada rodada, computa-se o chamado excesso de demanda definido como:

$$
A(t)=\sum_{i=1}^{N} a_{i, s}^{\mu(t)}
$$

em que, $a_{i, s}^{\mu(t)}$ representa a decisão do i-ésimo jogador devido à estratégia $\mathrm{s}^{*}$ (aquela com maior payoff entre todas). Note que o conjunto $\mathrm{A}(\mathrm{t})$, para $\mathrm{t}=0$, 1,2 ,...forma uma série temporal. $\mathrm{O}$ desvio padrão do excesso de demanda $\mathrm{A}(\mathrm{t})$ será denotado por $\sigma$, e representa uma medida da eficiência do sistema na distribuição de recursos (SAVIT; MANUCA; RIOLO, 1999). Quanto menor $\sigma$, mais amplo é o grupo minoritário.

O comportamento de $\sigma$ apresenta propriedades muito interessantes, conforme se varia m (SAVIT; MANUCA; RIOLO, 1999). Se $\sigma$ fosse calculado para a série descrita anteriormente, porém com os agentes tomando decisões de forma aleatória, o resultado seria uma distribuição de probabilidade do tipo binomial, em que $\sigma=\sqrt{N \cdot p(1-p)}$, sendo $\mathrm{p}$ a probabilidade de um agente pertencer ao grupo vencedor. Na Figura 1, tem-se o valor de $\sigma$ em função de $\mathbf{m}$, com $\mathbf{N}=101$ e $\mathbf{S}=2$. Para um dado $\mathbf{m}$, tem-se um conjunto de pontos representando 30 realizações independentes.

Analisando a Figura 1, pode-se destacar:

- Para m pequeno, o valor médio de $\sigma$ é bem maior que o desvio padrão do jogo com escolha aleatória ( $\sigma=5$, linha pontilhada no gráfico). Existe também, nesse caso, para o mesmo m, uma grande dispersão dos valores de $\sigma$;

- Para $\mathbf{m}=6$, o valor médio de $\sigma$ atinge um ponto de mínimo, e esse valor é menor que aquele calculado para o jogo com escolha aleatória; e

- Para valores de $\mathbf{m}>6$, o valor médio de $\sigma$ volta a crescer, e para $\mathrm{m}$ grande, $\sigma \rightarrow 5$. Observa-se também, para um mesmo $\mathbf{m}$, uma queda acentuada na dispersão dos valores de $\sigma$.

Outro fato interessante é que a dependência de $\sigma$, com o tamanho da memória m observada acima, é mais bem descrita por outra grandeza denotada por $\alpha$, que mede a complexidade do sistema. Construindo-se gráficos de $\sigma$ como função de $m$ para vários valores de $\mathbf{N}$, verifica-se que a forma geral da Figura 1 se mantém, mas o valor de $m_{c}$ é proporcional a $\ln \mathrm{N}$ e os valores de $\sigma$ e de sua dispersão $\Delta \sigma$ têm comportamentos diferentes conforme a região. Para $\boldsymbol{m}<m_{\mathrm{c}}, \sigma$ e $\Delta \sigma$ são proporcionais a $\mathbf{N}$, e para $\mathbf{m} \geq m_{\mathrm{c}}, \sigma$ e $\Delta \sigma$ são proporcionais a $\sqrt{N}$ (SAVIT; MANUCA; RIOLO, 1999). Os autores Savit, Manuca e Riolo (1999) descobriram que $\frac{\sigma^{2}}{N}$ é função apenas de $\frac{2^{m}}{N} \equiv \alpha$. Isso pode ser observado na Figura 2, construída

utilizando $\mathbf{S}=2$ e vários valores de $\mathbf{N}$ e $\mathbf{m}$, em uma escala log-log. Interessante notar que os pontos caracterizam o desenho de uma curva com o mesmo aspecto daquela imaginada para interpolar os valores médios de $\sigma$ (para um dado $\mathbf{m}$ ) na Figura 1, e que 
possui ponto de mínimo $\frac{2^{m_{c}}}{N} \equiv \alpha_{c}$ separando as duas regiões em que o sistema tem comportamentos diferentes.

\section{Interpretação geométrica}

Para explicar a curva típica das Figuras 1 e 2, e a distinção do comportamento de $\sigma$ acima e abaixo do ponto de mínimo, faz se uma exploração da estrutura de cooperação do Jogo da Minoria a partir de uma abordagem geométrica.
O espaço de estratégias pode ser representado em um hipercubo booleano de dimensão $2^{\mathrm{m}}$, cujos pontos contêm as $2^{2^{m}}$ distintas estratégias do Jogo da Minoria (ZHANG, 1998). Tomando nesse hipercubo duas estratégias vizinhas, que difiram suas prescrições de ação para apenas um determinado $\mu$, ou seja, as estratégias são diferentes em 1 bit apenas, diz-se que a distância de Hamming entre elas é unitária. Esse tipo de medida de distância conta o número de bits diferentes entre duas estratégias.

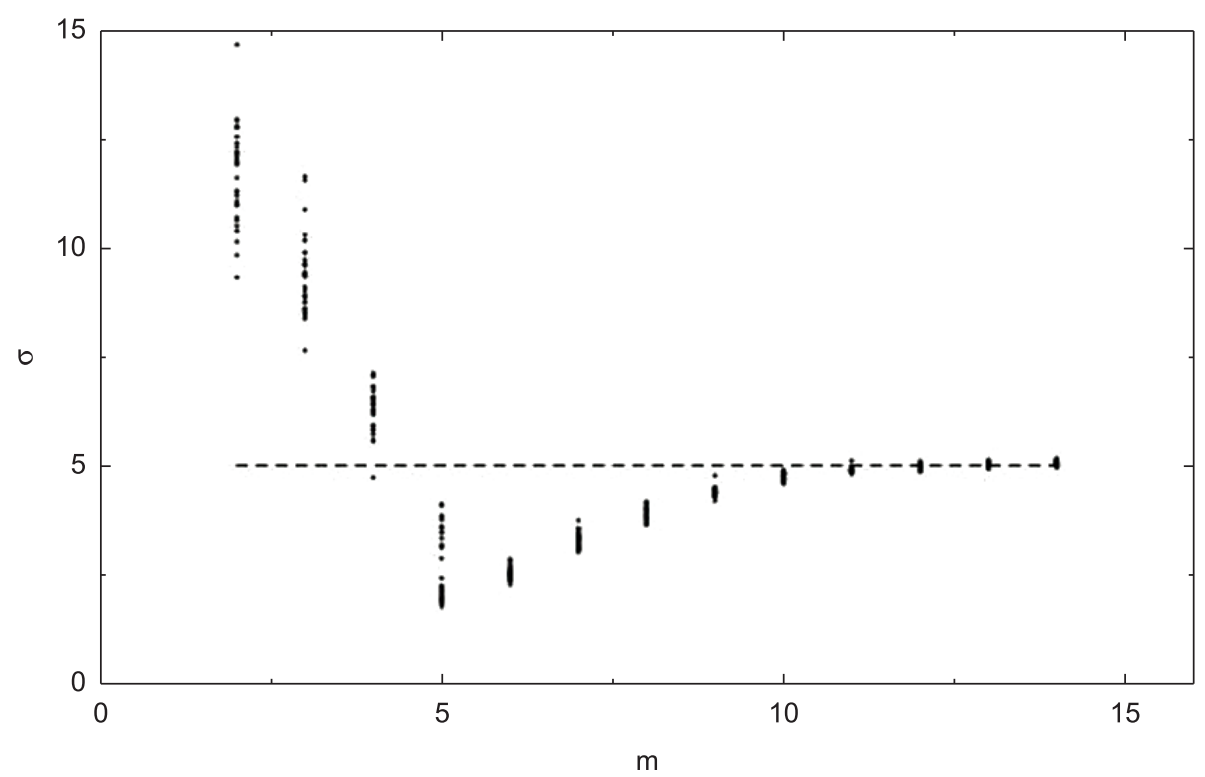

Figura 1. $\sigma$ como função de m para $N=101$ e $\mathrm{S}=2$, mostrando 30 realizações independentes. $\mathrm{O}$ valor de $\sigma$ para cada realização é denotado por um ponto. A linha pontilhada horizontal representa o valor de $\sigma$ para uma realização com comportamento aleatório.

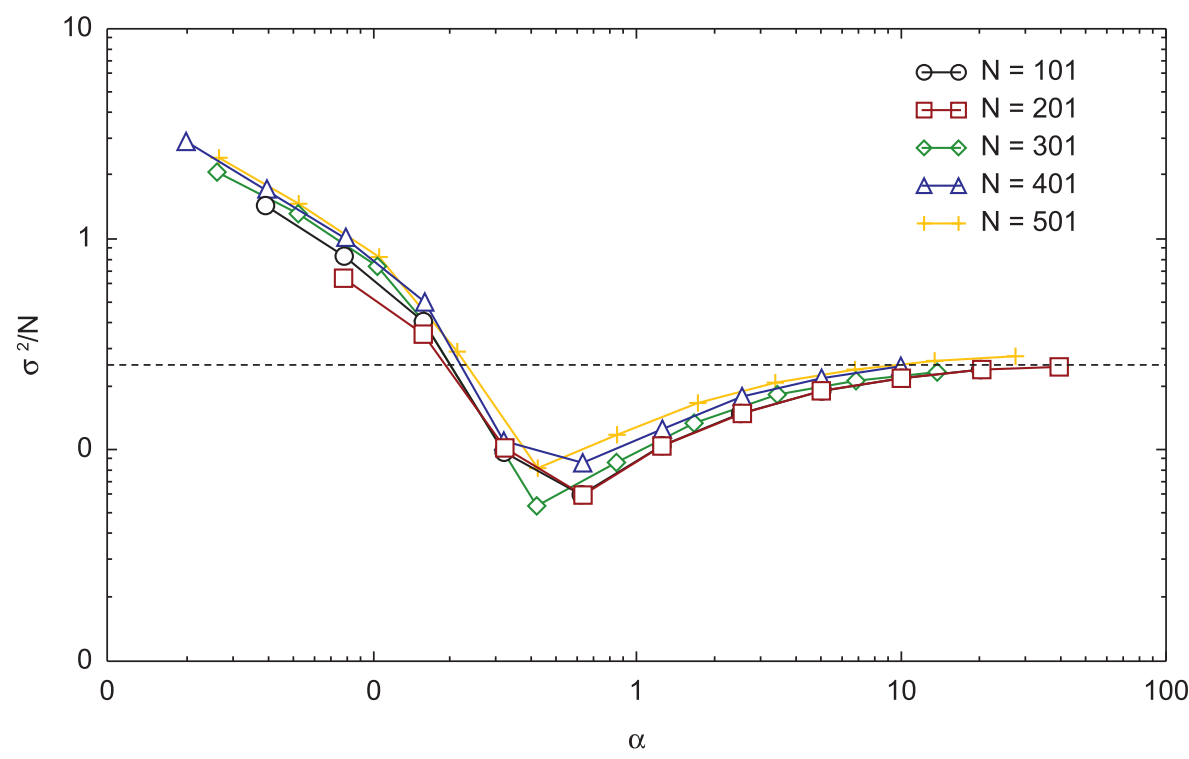

Figura 2. $\sigma^{2} / \mathrm{N}$ como função de $\alpha \equiv 2^{\mathrm{m}} / N$ para vários valores de $N$. Observa-se que todas as curvas têm um comportamento universal. 
Tomando $s$ e t como estratégias pertencentes ao hipercubo $H_{m}$, a distância de Hamming pode ser escrita como (CHALLET; ZHANG, 1998):

$$
D_{m}(s, t)=\sum_{i=1}^{2^{m}}|s(i)-t(i)|
$$

Se a distância for normalizada, tem-se $\mathrm{d}_{\mathrm{m}}(\mathrm{s}, \mathrm{t})=\mathrm{D}_{\mathrm{m}}(\mathrm{s}, \mathrm{t}) / 2^{\mathrm{m}}$.

Outra maneira de escrever a distância de Hamming é a partir dos agentes. Tomando dois agentes, i e j (CHALLET; MARSILI; ZHANG, 2000):

$$
\overline{d_{i, j}}=\frac{\overline{\left(a_{i}-a_{j}\right)^{2}}}{4}=\frac{1}{2}-\frac{1}{2} \overline{a_{i} a_{j}} .
$$

$\mathrm{O}$ traço sobrescrito representa uma média da variável em relação a $\mu$ e a letra $a$ representa a ação tomada pelo agente.

Pequenas distâncias de Hamming significam a existência de estratégias altamente correlacionadas, e jogadores que as possuem tendem a obter a mesma decisão. Por outro lado, se duas estratégias são descorrelacionadas, as decisões serão coincidentes com probabilidade $1 / 2$.

Uma medida do grau de diversidade (ou independência), existente em um conjunto de estratégias, é dada pela contagem das suas estratégias descorrelacionadas (ZHANG, 1998). Assim, é interessante proceder a essa contagem a partir do hipercubo booleano. Existe entre as estratégias um subconjunto $\mathbf{A}$ de $2^{\mathrm{m}}$ pares de pontos em que, para cada par, a distância de Hamming é máxima, ou seja, esses pares são anticorrelacionados, dado que as duas estratégias de um par apresentam ações opostas para um mesmo $\mu$. Mais ainda, a distância entre qualquer das estratégias de $\mathbf{A}$ com outra estratégia que não seja a sua antípoda será metade da distância máxima de Hamming, ou seja, $2^{\mathrm{m}-1}$, portanto mutuamente independentes. É necessário observar que é possível formar subconjuntos que tenham estratégias anticorrelacionadas, porém, as outras distâncias medidas nesse grupo não serão descorrelacionadas.

Existe uma forma de construção que permite obter os elementos que compõem o subconjunto $\mathbf{A}$. Tomam-se inicialmente as possíveis estratégias para o caso $\mathrm{m}=1$, conforme a Figura 3 .

Pode-se observar que cada estratégia contém um vetor ( $2^{\mathrm{a}}$ coluna) cujas componentes são as ações. Cada um desses vetores irá gerar dois novos, que possuirão o dobro do tamanho do vetor original. Os novos vetores surgem da concatenação $(\otimes)$ do vetor original, ora com ele próprio, ora com o seu antípoda. A Figura 4 mostra o resultado da aplicação dessa regra no vetor ação que está representado na estratégia (a) da Figura 3. Assim, observa-se que $[0,0] \otimes[0,0]=[0,0,0,0]$, (vetor ação da estratégia (e)) e que $[0,0] \otimes[1,1]=[0,0,1,1]$ (vetor ação da estratégia (f)), ambas da Figura 4.
Portanto, de forma geral, o subconjunto A, que contém $2^{(\mathrm{m}+1)}$ elementos, é construído de forma recorrente utilizando as operações:

$$
\begin{aligned}
& V^{(j)} \otimes V^{(j)} \rightarrow V^{\left(2^{*} j\right)} ; \\
& V^{(j)} \otimes \overline{V^{(j)}} \rightarrow V^{\left(2^{*} j\right)} ;
\end{aligned}
$$

Em que $\bar{V}_{i}=1-V_{i}$ e j representa a ordem $2^{\mathrm{m}}$, ou seja, no exemplo dado, os vetores de ordem 4 foram obtidos daqueles de ordem 2. Da mesma forma, são construídos os de ordem mais alta.

O número de pontos do subconjunto $\mathbf{A}, N_{0}=2^{\mathrm{m}+1}$, representa um espaço reduzido de estratégias, que desempenha um importante papel no modelo do Jogo da Minoria. A ideia é comparar $N_{0}$ com o número de estratégias na população N.S (ZHANG, 1998):

1. $N S>N_{0}$ (região saturada) - Os jogadores têm à disposição estratégias positivamente correlacionadas para utilizarem. O efeito de manada (muitos agentes fazendo a mesma coisa) é inevitável a despeito da adaptabilidade dos (a)

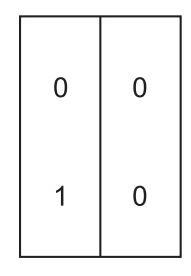

(C)

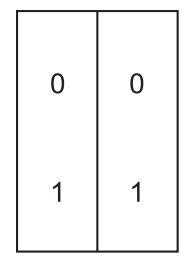

(b)

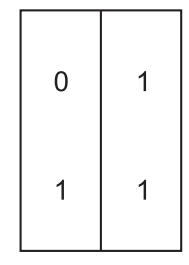

(d)

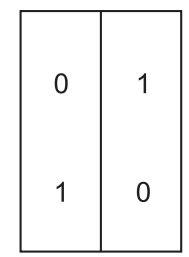

Figura 3. As quatro possíveis estratégias para $m=1$.
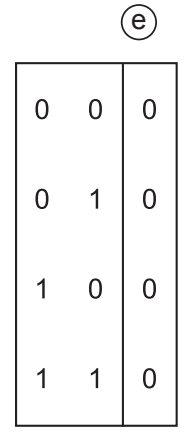

(f)

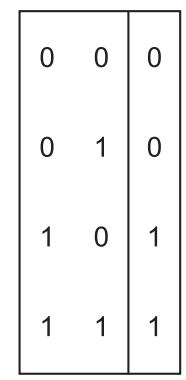

Figura 4. As duas novas estratégias criadas a partir do vetor ação [0,0], com $m=2$. 
jogadores e resultará em flutuações maiores que aquelas geradas por um processo do tipo caminho aleatório;

2. $N S \sim N_{0}$ (região crítica ou de cooperação) - As estratégias utilizadas pelos $N$ jogadores são bastante independentes e uma pequena parte que está anticorrelacionada possibilita a obtenção de decisões opostas; e

3. $N S<<N_{0}$ (região aleatória) - A anticorrelação está fortemente presente e os jogadores parecem utilizar estratégias aleatórias.

Tomando $\mathrm{S}=2$, o caso (2) representará o ponto de

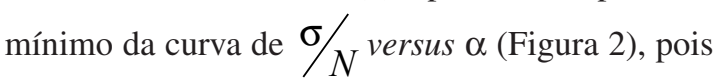
na região de cooperação $N_{0} / N S=\alpha_{c} \sim 1$. De forma geral, $\alpha=N_{0} / N S$ e os resultados obtidos por Savit, Manuca e Riolo (1999) podem ser explicados pela interpretação geométrica de Zhang (1998), conforme exposto anteriormente de (1) a (3). Outra explicação para este comportamento de $\sigma$ foi realizada de forma independente por Hart, Jefferies e Johnson (2001).

\section{A transição de fase}

Embora o excesso de demanda tenha valor médio temporal nulo, $\langle A\rangle=0$, o desvio padrão exibe um comportamento complexo, conforme discutido na seção anterior. A partir desse comportamento, pode-se distinguir dois tipos de resposta do sistema, um acima e outro abaixo do valor crítico $\alpha_{c}$, caracterizado pelo valor em que $\sigma$ é mínimo. Os autores Savit, Manuca e Riolo (1999) e Manuca et al. (2000) encontraram algo muito mais interessante que distingue as duas regiões. Eles procuraram saber se existem padrões preditivos ao longo da série de excesso de demanda $A(t)$. Para isso, mapearam A(t) em uma série temporal $\mathrm{G}(\mathrm{t})$ binária em que 0 representa os casos em que o grupo minoritário foi dos vendedores e 1 o dos compradores. A partir de $\mathrm{G}$, calcula-se a probabilidade condicional $P\left(1 \mid \mu_{k}\right)$, que é a probabilidade do grupo minoritário ser o de compradores (1) no tempo $\mathrm{t}+1$, dado um determinado estado $\mu$.

Foi simulado um jogo $\operatorname{com} \mathbf{N}=101, \mathbf{m}=3$ e $\mathbf{S}=2$ e dois casos foram analisados. Primeiro, perguntou-se se um agente com memória $\mathbf{k}=3=\mathbf{m}$ poderia prever probabilisticamente o grupo vencedor no tempo $t+1$, simplesmente calculando a probabilidade condicional $P\left(1 \mid \mu_{k}\right)$, para ao menos um estado $\mu$. O resultado obtido está mostrado na Figura 5a. Nota-se que $P\left(1 \mid \mu_{k}\right)=\frac{1}{2}$ para todo estado $\mu_{k}$, ou seja, nessas condições nã̃o parece ser possível prever o próximo bit para nenhum valor de $\mu_{k}$. O segundo caso foi analisar a possibilidade de predição, caso exista um agente infiltrado com memória $\mathbf{k}=4$, isto é, acima daquela utilizada para gerar a série $\mathrm{G}$. A hipótese é que um agente com maior capacidade de processamento, ou informação, pudesse arbitrar sobre os demais. $\mathrm{O}$ resultado deste segundo caso está na Figura 5b. Nesse experimento, $P\left(1 \mid \mu_{k}\right)$ é diferente de $\frac{1}{2}$, indicando a
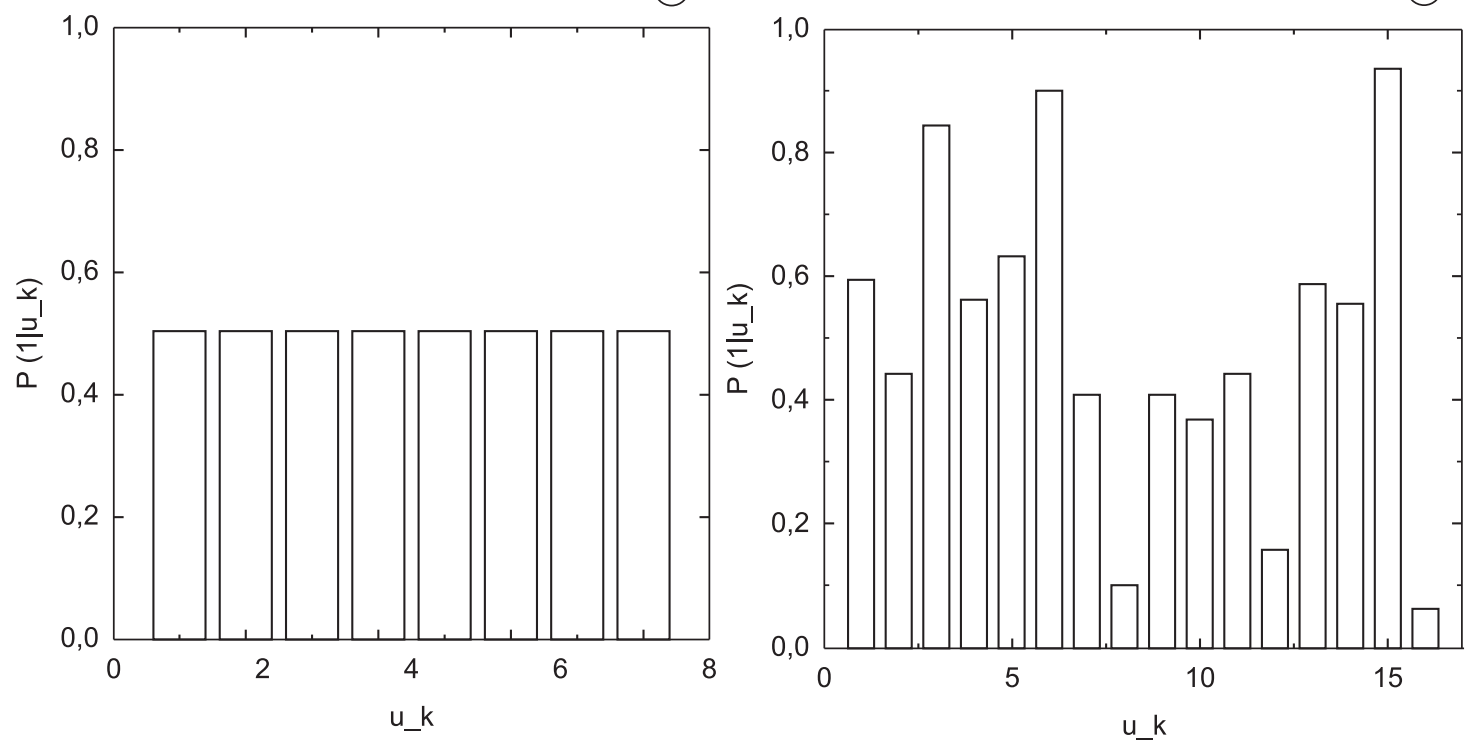

Figura 5. a) Histograma da probabilidade condicional $P\left(1 \mid \mu_{k}\right) \operatorname{com} k=3$ para uma série com $m=3$. Os valores binários de $\mu$ estão representados na base 10 . b) Histograma da probabilidade condicional $P\left(1 \mid \mu_{k}\right)$ com $k=4$ para uma série com $m=3$. 
possibilidade de obter mais ganhos que os agentes com memória reduzida. Contudo, supondo igualdade de memória, pode-se dizer que no primeiro experimento o mercado é eficiente, já que nenhuma estratégia com $\mathrm{m} \leq 4$ pode obter sucesso maior que $50 \%$.

Repetindo essa análise, porém adotando agora $\boldsymbol{m} \geq \boldsymbol{m}_{\mathrm{c}}$ e, em particular, para um jogo com os parâmetros $\mathbf{N}=101$ e $\mathbf{S}=2$ e $\mathbf{m}=6$, observa-se pela Figura 6, que, diferentemente do que aconteceu na Figura 5a, existe um padrão e todos os agentes podem acessá-lo. No sentido descrito anteriormente o mercado não é eficiente.

A formalização matemática deste problema foi obtida por Challet e Marsili (1999) com uma explicação muito simples. Segundo eles, para cada $\mu$ existem agentes que sempre tomam a mesma decisão. Isso acontece porque sua melhor estratégia congela para determinado $\mu \mathrm{e}$, assim, preconizam a mesma ação a ser tomada quando o estado $\mu$ aparece. Isso produz um viés em $\boldsymbol{A}$ sempre que $\mu_{\mathrm{t}}=\mu$. Para medir esse viés, é definido o parâmetro de ordem que identifica a transição de fase do modelo (CHALLET; MARSILI, 1999; CHALLET; MARSILI; ZECCHINA, 2000):

$$
H=\frac{1}{P} \sum_{\mu=1}^{P}\langle A \mid \mu\rangle^{2}=\overline{\langle A\rangle^{2}}
$$

em que $\langle A \mid \mu\rangle$ é a média condicional de $A$ dado que $\mu_{\mathrm{t}}=\mu$. A barra sobrescrita em $\overline{\langle A\rangle^{2}}$ é uma simplificação para a média em $\mathrm{P}$, ou seja, substitui o termo $\frac{1}{p} \sum_{\mu=1}^{p}$.
A variável $\mathrm{H}$ é chamada de previsibilidade (RODRIGUES, 2005) e mede a presença de informação ou arbitragem no sinal de $\boldsymbol{A}$ (CHALLET; MARSILI, 1999). O comportamento de $H$ em função de $\alpha$ é dado na Figura 7.

Observa-se, basicamente, que $H=0$ para $\alpha<\alpha_{c}$ e $\mathrm{H}>0$ para $\alpha>\alpha_{\text {c }}$. Isso é uma marca da transição de fase. Nesse último caso, um agente pode detectar ou explorar a informação existente, indicando que uma de suas estratégias seja mais correlacionada com $\langle A \mid \mu\rangle$ que as outras. Outro fato que chama a atenção é que $\mathrm{H}$ vai para zero exatamente no ponto em que $\sigma$ é mínimo. A dinâmica do modelo é tal que, ao diminuir $\alpha$, os agentes passam a ter maior capacidade de explorar a informação e exaurir a previsibilidade, tornando o mercado cada vez mais eficiente do ponto vista informacional. Porém, para $\alpha$ na região subcrítica ocorre uma maior dificuldade de coordenação ou cooperação e o sistema se torna ineficiente do ponto de vista de distribuição de recursos.

Para finalizar, pode-se dizer que é intrigante que um modelo para explicar comportamento de agentes econômicos possa exibir propriedades conhecidas e descritas pela antiga termodinâmica. Isso sugere que se possa conhecer no futuro modelos para ciências sociais e econômicas simples o suficiente para evoluírem e incorporarem característica cada vez mais realística, mas não tão simples para poderem capturar comportamentos complexos. Além disso, estes modelos vão permitir a adoção de uma linguagem comum para as ciências da natureza e da área de humanidades. Essa agenda vem sendo desenvolvida em novas áreas que congregam a chamada ciência da complexidade.

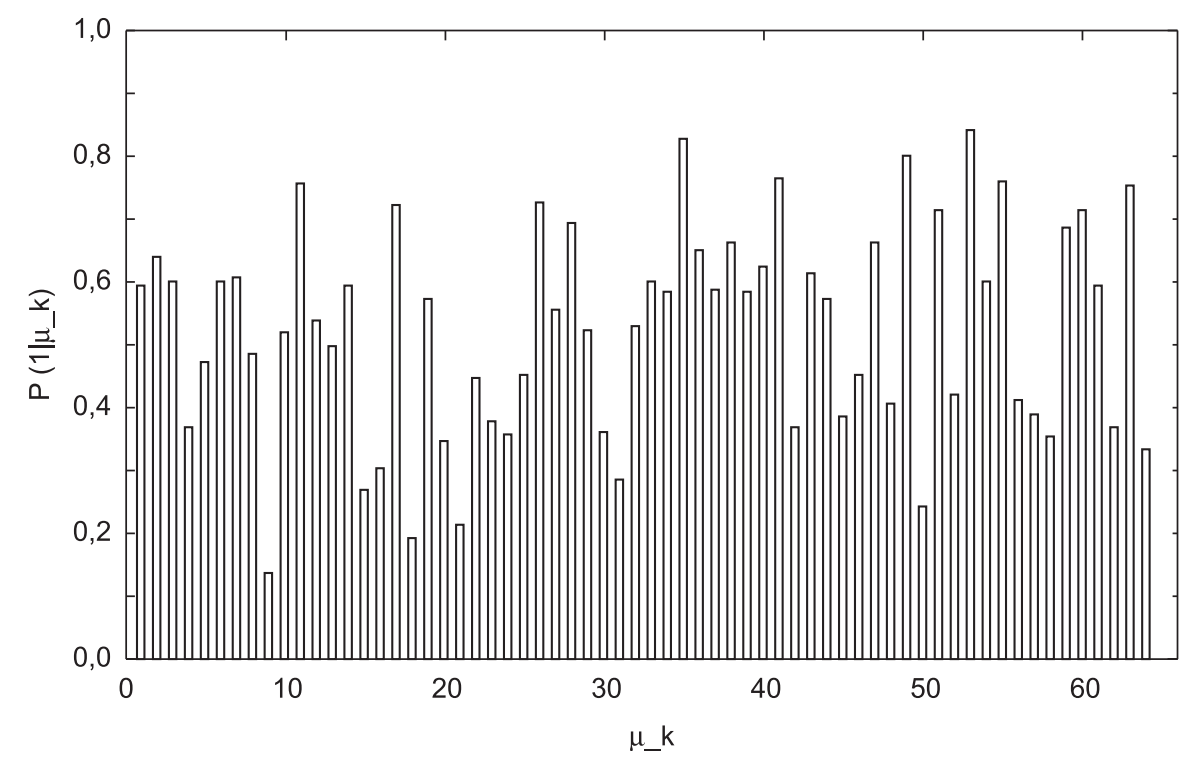

Figura 6. Histograma da probabilidade condicional $P\left(1 \mid \mu_{k}\right)$ com $k=6$ para uma jogada com $m=6$. Os valores binários de $\mu$ estão representados na base 10 . 


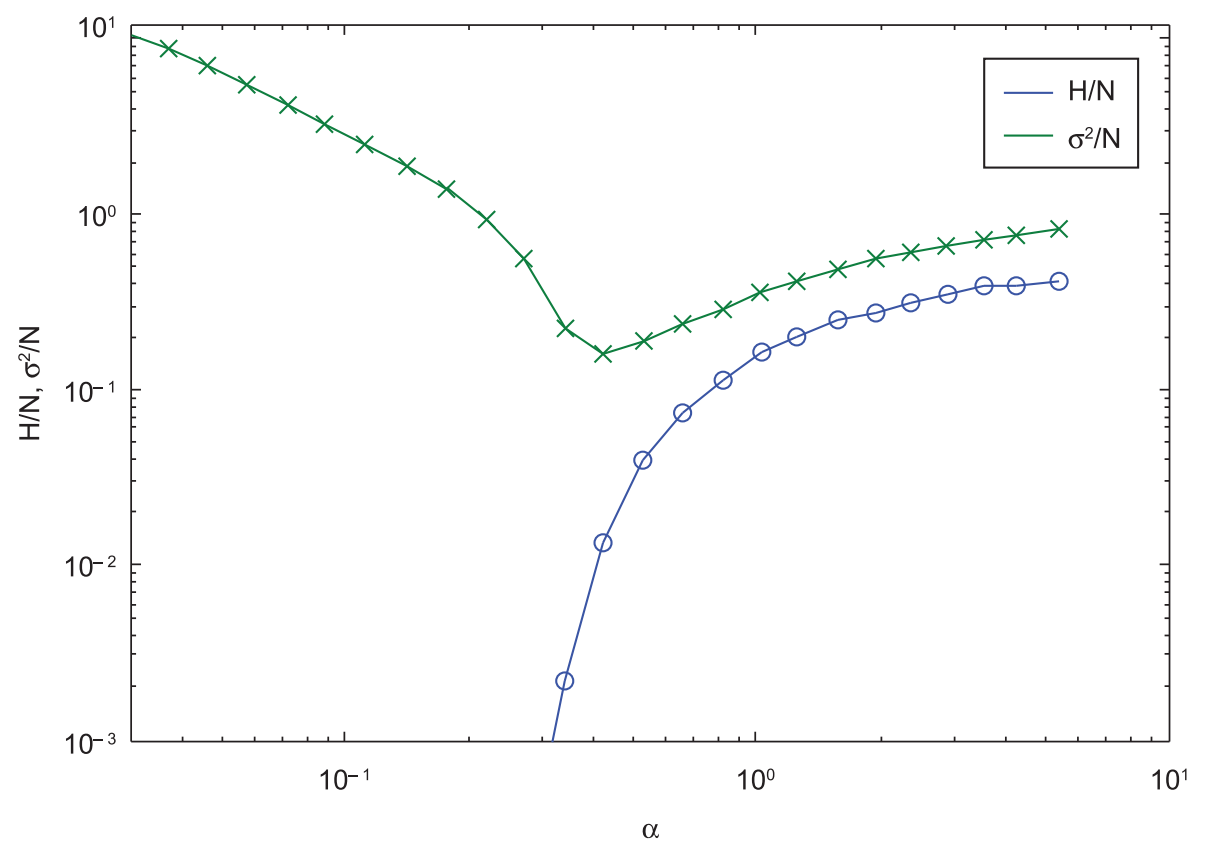

Figura 7. Os círculos abertos representam o comportamento de $H / N$ enquanto o símbolo + representa $\sigma 2 / \mathrm{N}$, ambos contra $\alpha \equiv 2^{\mathrm{m}} / N$, com $\mathrm{m}=7$. Note que $\mathrm{H}$ converge para zero exatamente quando $\sigma$ é mínimo, ou seja, para $\alpha=\alpha_{\mathrm{c}} \approx 0,34$.

\section{O modelo Grande Canônico}

O Jogo da Minoria apresentado anteriormente não reproduz todos os fatos estilizados por ser uma versão muito simplificada da realidade. Para torná-lo um pouco mais realístico, deve-se permitir que os agentes possam sair do mercado quando suas estratégias levam-nos, em média, a perdas em torno de um valor $\varepsilon$. Este valor pode ser a taxa de juros que ele ganharia se optasse por outro investimento como a poupança. Embora seja permitido que os agentes saiam do jogo, nada impede que eles continuem acompanhando o mercado e, caso percebam que as suas estratégias possam levá-los a ganhar uma taxa superior a $\varepsilon$, que seja permitido que eles voltem ao jogo. A possibilidade do número de agentes variar levou os autores a chamá-lo de modelo Grande Canônico em analogia com a situação em mecânica estatística que recebe o mesmo nome quando o número de partículas em um sistema em contato com um banho térmico varia. A outra inovação nessa nova versão será a presença de um novo tipo de agente chamado de produtor, cuja motivação será discutida logo a seguir.

Aparentemente, o mercado tem o comportamento de um jogo de soma zero, em que alguns ganham à medida que outros perdem. Em geral, entretanto, é razoável pensar que a maioria dos participantes do mercado beneficia-se dessa dinâmica, pela própria persistência do processo. Então, caberia perguntar: quem injeta dinheiro no mercado? A resposta surge quando se procede à divisão de seus participantes em dois tipos: os produtores e os especuladores (ZHANG, 1999).

Os produtores participam do mercado observando necessidades que são alheias a sua dinâmica. $\mathrm{Na}$ realidade, o termo é conveniente para designar desde indivíduos que se utilizam do mercado para fazer hedge até o turista que busca fazer câmbio.

Já os especuladores buscam vantagem na movimentação do mercado, tentando lucrar com um processo de arbitragem. Exemplos são grandes instituições financeiras, fundos de hedge ou até mesmo pessoas físicas, que, por meio de corretoras de valores, atuam no mercado.

Resumidamente, pode-se caracterizar os dois tipos de agentes da seguinte forma:

\section{- Produtores}

- Injetam elementos de previsão nas flutuações aparentemente aleatórias do mercado;

- Esse agente tem interesse em negócios externos ao mercado;

- Participam do mercado para suas próprias necessidades de um modo previsível, indiferentes às pequenas flutuações de preço; $\mathrm{e}$

- Possuem perspectiva de longo prazo.

\section{- Especuladores}

- Compram e vendem ativos sem se preocupar com seu valor intrínseco; 
- São exclusivamente dirigidos pela perspectiva de ganhar com as flutuações de preços;

- Exploram a previsibilidade introduzida pelos produtores; e

- Fazem transações visando a pequenos retornos num horizonte de curto prazo.

À primeira vista, parece que o produtor injeta dinheiro no mercado, e o especulador, utilizando-se de alguma estratégia, se apropria desse valor. Nesses termos, comparando com um sistema biológico, o especulador seria um parasita. Na verdade, a analogia de associação biológica que existe entre esses agentes é a simbiose (ZHANG, 1999). O especulador exerce uma função social, mesmo sem querer, de tornar o mercado líquido.

Nesse processo de simbiose, os produtores proporcionam informação e ganhos positivos aos especuladores, enquanto que os especuladores reduzem as perdas dos produtores providenciando liquidez no mercado.

Essa configuração do mercado dividido em dois tipos de agentes, produtores e especuladores, foi incorporada ao Jogo da Minoria (CHALLET; MARSILI; ZHANG, 2000; 2001a). Os produtores são representados por agentes com apenas uma estratégia, $\mathrm{s}=1$ (CHALLET; MARSILI; ZHANG, 2000, 2005). Portanto, seu comportamento é determinístico: dado certo $\mu$, representado os grupos minoritários em dado horizonte temporal, o produtor agirá sempre da mesma maneira. Já o especulador é um agente típico do Jogo da Minoria tradicional, possuindo várias estratégias (CHALLET; MARSILI; ZHANG, 2000, 2005). Esse agente tenta extrair do jogo as informações que são injetadas pelo produtor.

A característica de permitir a flutuação do número de especuladores torna o Jogo da Minoria Grande Canônico capaz de apresentar crashes em suas séries de retornos (CHALLET; MARSILI; ZHANG, 2005, 2001a). A responsável pelos grandes movimentos de preços é a multidão de agentes inativos que em dado instante apenas observa o movimento de preços do mercado e em um instante posterior pode, ao mesmo tempo, entrar no mercado para negociar. Essa atitude sincronizada ocorre porque, enquanto esses agentes observam o mercado, eles conseguem apenas perceber a dinâmica dos agentes que estão ativos, sem ter acesso à configuração de mercado caso fossem levadas em consideração as estratégias dos outros agentes que também não estão negociando: um inativo não consegue, portanto, "sentir" o outro. Então, os inativos que possuem estratégias semelhantes são atraídos para o mercado ao mesmo tempo e podem, assim, entrar no mercado de forma sincronizada, gerando um crash.

Um modelo de Jogo da Minoria Grande Canônico é apresentado em (FERREIRA et al., 2005). Ele consiste de $\mathrm{N}$ agentes interagindo, em que $N_{\mathrm{p}}$ são os produtores e os remanescentes $\mathrm{N}_{\mathrm{s}}=\mathrm{N}-\mathrm{N}_{\mathrm{p}}^{\mathrm{p}}$ são os especuladores. Os agentes são dotados com $\mathrm{s}=0, \ldots, \mathrm{S}$ estratégias que são mantidas fixas desde o início. As estratégias permitem que eles tomem decisões como comprar, vender ou não negociar a cada tempo t.

Para ser bem sucedido no jogo, cada agente procura permanecer no grupo da minoria, isto é, comprar ativos quando a maioria vende e vice-versa. Na realidade, o mecanismo de mercado é mais complexo. Apesar disso, a regra da minoria lembra a lei da oferta e demanda. Por simplicidade, mapeia-se o histórico dos preços $p(\mathrm{t})$ em uma sequência binária. Cada bit representa um sinal da variação de preços entre $t-\tau$ e t, para uma conveniente escala $\tau$. Padrões podem ser construídos a partir da sequência binária pela definição de um vetor de tamanho m que representa um pedaço da sequência. O número total de diferentes padrões é $\mathrm{P}=2^{\mathrm{m}}$. Esses padrões são dependentes do tempo e correspondem à informação pública que é denotada por $\mu(\mathrm{t})$. A estratégia é projetada para ler uma informação $\mu(t)$ e retornar ao agente uma decisão correspondente.

No caso dos especuladores, as decisões são denotadas por $a_{i, s}^{\mu}= \pm 1,0$, em que $i=1, \ldots, N_{\mathrm{s}}$; enquanto a decisão dos produtores é denotada por $b_{j}^{\mu}= \pm 1$, em que $j=1, \ldots, N_{\mathrm{p}}$. Observa-se que os produtores têm somente uma estratégia que depende da informação, $\mu$, portanto, eles estão sempre negociando, isto é, comprando e vendendo ativos. Por outro lado, especuladores têm mais que uma estratégia, além de contar com a estratégia nula $\mathrm{s}=0$, que permite a eles não negociar, $a_{i, 0}^{\mu}=0$. A cada tempo t, todos os jogadores tomam suas decisões individuais e então é computado o excesso de demanda $A(t)$, que é definido como:

$$
A(t)=\sum_{j=1}^{N_{p}} b_{j}^{\mu(t)}(t)+\sum_{i=1}^{N_{s}} a_{i, \hat{s}}^{\mu(t)}(t)
$$

O desempenho das estratégias é dado pela função de pontuação:

$$
U_{i, s}(t+1)=U_{i, s}(t)-a_{i, s}^{\mu}(t) A(t)+\epsilon \delta_{0, s}
$$

em que $\hat{s}$ corresponde ao valor máximo de $U_{i, s}$ no tempo t, $\hat{s}=\max _{s} U_{i, s}$, e $\epsilon>0$ é a taxa de juros recebida por não negociar e $\epsilon<0$ significa um incentivo a negociar.

Esse modelo apresenta fatos estilizados como agrupamento de volatilidade (volatility clustering), ausência de autocorrelação linear, decaimento lento da autocorrelação dos retornos absolutos e caudas gordas na distribuição de probabilidade conforme a Figura 8. Outras abordagens do modelo Grande Canônico também apresentam fatos estilizados (CHALLET; MARSILI; ZHANG, 2001a, b; CHALLET; MARSILI, 2003; BIANCONI et al., 2008). 
(a)

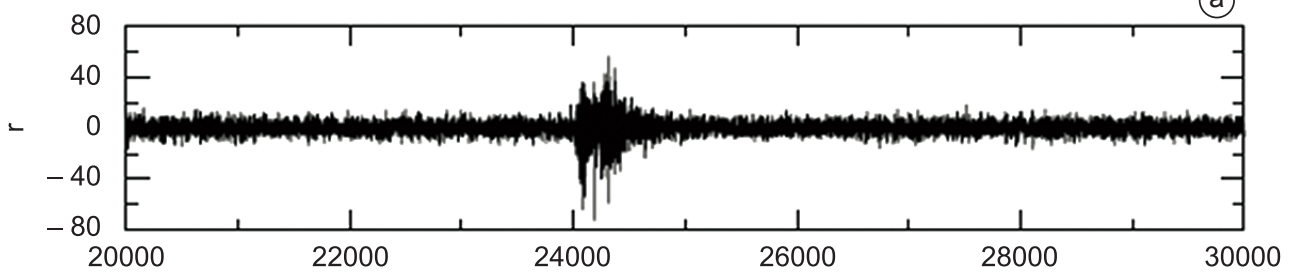

Time
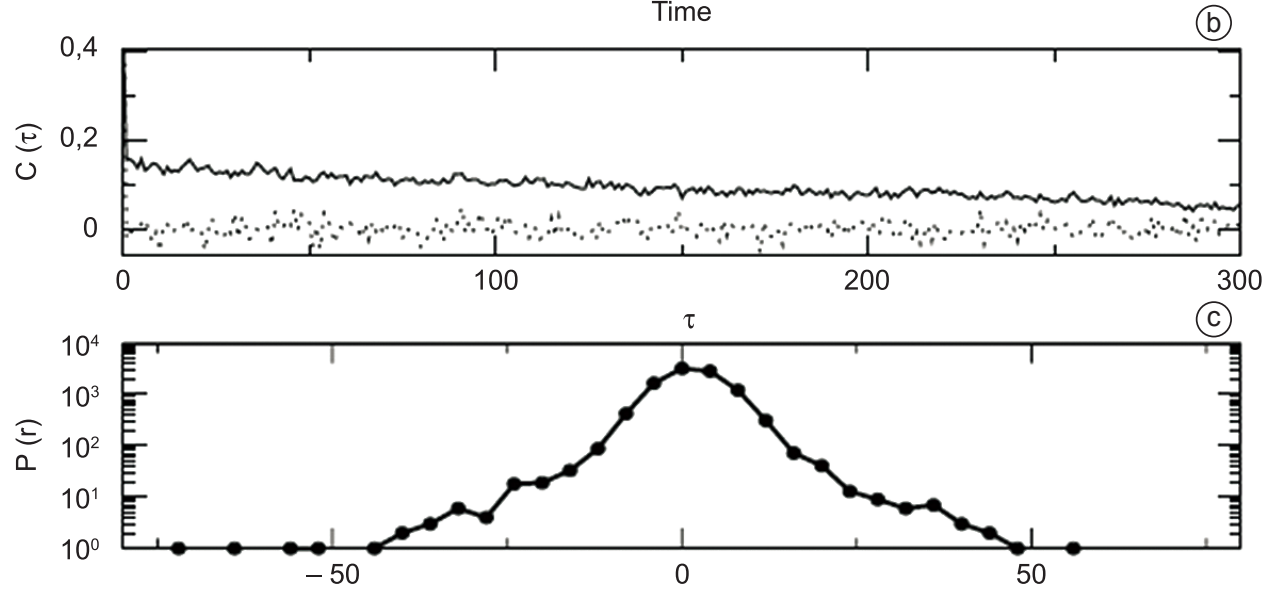

Figura 8. a) Evolução temporal do retorno. b) Autocorrelação (linha pontilhada) e autocorrelação dos valores absolutos (linha contínua) como função de $\tau$. c) Distribuição de probabilidade dos retornos $P(r)$ como função de $r$. Os valores dos parâmetros são $\mathrm{N}=1000, \mathrm{P}=100, \theta_{\text {máx }}=100, \rho=0.6$. Em c) observam-se caudas gordas e assimetria negativa. Fonte: Ferreira et al. (2005, p. 539).

Cada agente $i$ (especulador) tem uma percepção do valor fundamental do preço do ativo $\theta_{i}$. Essa é uma variável aleatória com distribuição uniforme no intervalo $\left[0, \theta_{\text {máx }}\right]$. A variável $\rho$ representa o percentual de indivíduos na população que são especuladores, $\rho=N_{s} / N$. Já o parâmetro $P$ limita a variável $\mu$, $\mu=0, \ldots \mathrm{P}-1$.

Observa-se, a partir dos resultados apresentados, que o Jogo da Minoria Grande Canônico e suas variantes são modelos que conseguem reproduzir fatos estilizados importantes que surgem no mercado financeiro real, o que é surpreendente, dada a simplicidade da dinâmica contida nesses modelos. É preciso salientar, porém, que a simplicidade não implica em facilidade na obtenção de resultados interessantes. Muitas vezes, alterações significativas do modelo, como propostas criativas de modificação da função de pontuação das estratégias (payoff das estratégias), que inicialmente parecem promissoras, podem redundar em realizações sem sentido. Contudo, esse tipo de modelo baseado em agentes consegue incorporar à sua dinâmica comportamentos que não estão contemplados em modelagens feitas a partir das equações diferenciais estocásticas que possuam como hipótese o movimento do tipo passeio aleatório para o preço de um ativo. Enfim, são bastante promissores os trabalhos desenvolvidos nessa área, que, a exemplo do Jogo da Minoria, tem pouco mais de uma década.

O Jogo da Minoria e sua versão Grande Canônica apresentam algo ainda mais intrigante que simplesmente reproduzir os fatos estilizados. Esses modelos exibem uma transição de fase à semelhança do que se observa na natureza quando se varia um parâmetro como, por exemplo, a temperatura, chamado pelos físicos de parâmetro de controle. Alterando esse parâmetro de controle, a água pode passar do estado líquido para o sólido ou gasoso. Há um valor da temperatura, para o qual ocorre a coexistência das três fases, que recebe o nome de ponto crítico. O mesmo acontece aqui para um valor de $\alpha=\alpha_{\text {c }}$. Challet e Marsili (2003) mostraram que os fatos estilizados ocorrem na vizinhança desse ponto crítico. Isso significa que o mercado na iminência de uma crise se auto-organiza próximo ao ponto crítico. Essa foi uma grande surpresa, pois na natureza se observam flutuações anômalas que levam ao surgimento de leis de escalas do tipo observado no mercado financeiro quando o sistema aproxima-se desse ponto crítico. Se de fato o mercado tiver essa propriedade, com base em tudo o que sabemos da mecânica estatística, as propriedades macroscópicas observadas nos dados (fatos estilizados) não devem depender de detalhes 
microscópicos. Isso implica que modelos mais simples poderão capturar os mecanismos que regem o mercado financeiro. Em outras palavras, o que realmente interessa para explicar essas regularidades são as propriedades presentes nas interações, ou seja, as próprias regras de interação. Isso faz com que os modelos de agentes sejam muito promissores, pois eles são definidos a partir da regra de interação entre os agentes, que parece ser a componente mais importante para entender os mecanismos que regem o mercado.

\section{Considerações finais}

Numa leitura crítica da teoria econômica neoclássica e da teoria financeira que fundamenta o mercado financeiro há de se perceber que os pressupostos nas quais elas se fundamentam estão incorretos ou não são muito realistas. Isso se deve, entre outras coisas, à busca de modelos matemáticos analíticos ou tratáveis. Para isso, são necessárias hipóteses simplificadoras que, de partida, ignorem os dados empíricos. Daí uma das explicações para a dificuldade que os economistas têm em prever o mercado. Além disso, modelos baseados em equilíbrio são contestados dentro da própria ciência econômica, que, atualmente, também busca construir modelos que abarquem o aspecto da dinâmica das variáveis econômicas.

Qualquer que seja a abordagem utilizada para se construir modelos, não é possível ignorar os dados. Um bom modelo para o mercado tem que ser capaz de reproduzir os fatos estilizados. Essas regularidades estatísticas foram apresentadas ao longo deste artigo. Pode-se dizer que um modelo que exiba tais propriedades produziu as evidências empíricas mínimas desejadas.

Buscou-se, neste artigo, apresentar um modelo protótipo para explicar o mercado financeiro chamado Jogo da Minoria e sua versão aprimorada, o Jogo da Minoria Grande Canônico. Este modelo, especificamente, é capaz de gerar séries de retornos com fatos estilizados como aqueles observados no mercado financeiro real. Com esse modelo, podemos gerar séries que possuam as mesmas regularidades estatísticas observadas em séries empíricas, como também mostrar que o mercado se auto-organiza de forma a se tornar um sistema crítico, o que representa aumentar a instabilidade do sistema (grandes flutuações). Em termos do mercado financeiro, essa é condição necessária para gerar as crises.

O principal objetivo deste artigo foi apresentar uma nova abordagem para a modelagem em Economia. Para poder evocar hipóteses mais realistas, a chamada modelagem baseada em agentes parece ser uma boa candidata a produzir a próxima geração de modelos para descrever o mercado.

\section{Referências}

ARTHUR, B. W. Inductive reasoning and bounded rationality: the El Farol problem. American Economic Review, v. 84, p. 406-411, 1994.

BAK, P.; PACZUSKI, M.; SHUBIK, M. Price variations in a stock market with many agents. Physica A, v. 246, p. 430-453, 1997. http://dx.doi.org/10.1016/ S0378-4371(97)00401-9

BIANCONI, G. et al. Multi-assetminotiy Games. Quantitative Finance, v. 8, p. 225-231, 2008. http:// dx.doi.org/10.1080/14697680701253039

BLACK, F.; SCHOLES, M. The Pricing of Options and Corporate Liabilities. Journal of Political Economy, v. 81, p. 637-654, 1973. http://dx.doi.org/10.1086/260062

BOUCHAUD, J. P.; POTTERS, M. Theory of financial Risk and Derivative Pricing From Statistical to Risk Management. Cambridge: Cambridge University Press; 2003. http://dx.doi.org/10.1017/ CBO9780511753893

BROCK, W.; LEBARON, B. Adynamical structural model for stock return volatility and trading volume. Review of Economics and Statistics, v. 78, p. 94-110, 1996. http://dx.doi.org/10.2307/2109850

CALDARELLI, G.; MARSILI, M.; ZHANG, Y.-C. A prototype model of stock exchange. EPL - Europhysics Letters, v. 40, p. 479-484, 1997. http://dx.doi. org/10.1209/epl/i1997-00491-5

CHALLET, D.; ZHANG, Y.-C. Emergence of cooperation and organization in an evolutionary game. Physica A, v. 246, p. 407-418, 1997. http://dx.doi.org/10.1016/ S0378-4371(97)00419-6

CHALLET, D.; ZHANG, Y.-C. On the minority game: analytical and numerical studies. Physica A, v. 256, p. 514-532, 1998. http://dx.doi.org/10.1016/ S0378-4371(98)00260-X

CHALLET, D.; MARSILI, M. Phase transition and symmetry breaking in the minority game. Physical Review E, v. 60, p. R6271-R6274, 1999. http://dx.doi.org/10.1103/ PhysRevE.60.R6271

CHALLET, D.; MARSILI, M. Criticality and market efficiency in a simple realistic model of the stock market. Physical Review E, v. 68, p. 036132, 2003. PMid:14524857. http://dx.doi.org/10.1103/ PhysRevE.68.036132

CHALLET, D.; MARSILI, M.; ZECCHINA, R. Statistical mechanics of systems with heterogeneous agents: minority games. Physical Review Letters, v. 84, p. 1824-1827, 2000. http://dx.doi.org/10.1103/ PhysRevLett.84.1824

CHALLET, D.; MARSILI, M.; ZHANG, Y.-C. Modeling market mechanism with minority game. Physica A, v. 276, p. 284-315, 2000. http://dx.doi.org/10.1016/ S0378-4371(99)00446-X

CHALLET, D.; MARSILI, M.; ZHANG, Y.-C. Stylized facts of financial markets and market crashes in minority games. Physica A, v. 294, p. 514-524, 2001a. http:// dx.doi.org/10.1016/S0378-4371(01)00103-0

CHALlET, D.; MARSILI, M.; ZHANG, Y.-C. Minority games and stylized facts. Physica A, 
v. 299 , p. $228-233$, 2001b. http://dx.doi.org/10.1016/ S0378-4371(01)00300-4

CHALLET, D.; MARSILI, M.; ZHANG, Y.-C. Minority

Games: interacting agents in financial markets. New York: Oxford University Press, 2005.

CONT, R. Empirical properties of asset returns: stylized facts and statistical issues. Quantitative Finance, v. 1, p. 223-236, 2001. http://dx.doi.org/10.1080/713665670

FERREIRA, F. F. et al. Agent-based model with heterogeneous fundamental prices. Physica A, v. 357, p. 534-542, 2005. http://dx.doi.org/10.1016/j.physa.2005.03.048

GOPIKRISHNAN, P. et al. Scaling of the distribution of financial market indices. Physical Review E, v. 60, p. 5305, 1999. http://dx.doi.org/10.1103/PhysRevE.60.5305

HART, M.; JEFFERIES, P. M.; JOHNSON, N. F. Crowdanticrowd theory of multi-agent market games. European Physical Journal B, v. 20, p. 547-550, 2001. http:// dx.doi.org/10.1007/s100510170237

ITÔ, K. On stochastic differential equations. Memoirs of the American Mathematical Society, v. 4, p. 1-51, 1951.

JOHNSON, N. F. et al. Application of multi-agent games to the prediction of financial time series. Physica A, v. 299, p. 222-227, 2001. http://dx.doi.org/10.1016/ S0378-4371(01)00299-0

LEVY, M.; LEVY, H.; SOLOMON, S. Microscopic simulation of the stock market: the effect of microscopic diversity. Journal of Physics, v. 5, p. 1087-1107, 1995.

LUX, T.; MARCHESI, M. Scaling and criticality in a stochastic multi-agent model of a financial market. Nature, v. 397, 498-500, 1999. http://dx.doi.org/10.1038/17290
MANTEGNA, R. N.; STANLEY, H. E. An Introduction to Econophysics: Correlationand Complexity in Finance. Cambridge: Cambridge University Press, 2000.

MANUCA, R. et al. The structure of adaptative competition in minority game. Physica A, v. 282, p. 559-608, 2000. http://dx.doi.org/10.1016/S0378-4371(00)00100-X

PALMER, R. G. et al. Artificial economic life: a simple model for a stockmarket. Physica D, v. 75, p. 264-274, 1994. http://dx.doi.org/10.1016/0167-2789(94)90287-9

RODRIGuES, A. G. A. Análise de um Modelo Microscópico para o Mercado Financeiro. 2005. 60 f. Dissertação (Mestrado em Física)-Instituto de Física Teórica, Universidade Estadual Paulista, São Paulo, 2005.

SAVIT, R.; MANUCA, R.; RIOLO, R. Adaptative competition, market efficiency, and phase transitions. Physical Review Letters, v. 82, p. 2203-2206, 1999. http://dx.doi.org/10.1103/PhysRevLett.82.2203

SCHACHERMAYER, W.; TEICHMANN, J. How close are the Option Pricing Formulas of Bachelier and Black-Merton-Scholes? Mathematical Finance, v. 18, p. 55-76, 2008.

TANG, L.-H.; HUANG, Z.-F. Modelling hig-frequency economic time series. Physica A, v. 288, p. 444-450, 2000. http://dx.doi.org/10.1016/S0378-4371(00)00442-8

ZHANG, Y.-C. Evolving models of financial markets. Europhysics News, v. 29, p. 51-54, 1998.

ZHANG, Y.-C. Toward a theory of marginally efficient markets. Physica A, v. 269, p. 30-44, 1999. http:// dx.doi.org/10.1016/S0378-4371(00)00442-8 


\section{Apêndice A. Fatos Estilizados do Mercado Financeiro}

Nas últimas décadas, a disponibilidade de dados financeiros de alta frequência (chegando à ordem de segundos) e a utilização de métodos computacionais permitiram um avanço substancial no estudo do comportamento do mercado financeiro (CONT, 2001; MANTEGNA; STANLEY, 2000; BOUCHAUD; POTTERS, 2003). A partir de observações empíricas, foram notadas determinadas regularidades estatísticas que permeavam os mais diversos tipos de ativos em diferentes locais e períodos analisados (CONT, 2001). O trabalho pioneiro de Mandelbrot, nos anos 1960, sobre a função de distribuição dos retornos de commodities já exibia um comportamento não gaussiano desses dados, assim como verificava que a forma funcional da distribuição não se alterava com a mudança da frequência da amostragem dos dados, quando analisados intervalos temporais de um dia até um mês (GOPIKRISHNAN et al., 1999). O conjunto de propriedades estatísticas apresentado pelas séries temporais de retorno e volatilidade dos diversos mercados financeiros foi denominado fatos estilizados (GOPIKRISHNAN et al., 1999; CONT, 2001). Entre os fatos estilizados das séries de retorno pode-se destacar: função de distribuição apresentando caudas gordas; ocorrência de assimetria ganho/perda; gaussianidade agregativa; caudas gordas condicionais e a ausência de autocorrelação (linear). Já as séries de volatilidade apresentam: decaimento lento da autocorrelação; intermitência; agrupamentos de volatilidade e efeito de alavancagem.

O modelo de dinâmica de preços mais comum assume que os incrementos de preços - ou seja, o retorno - segue um processo difusivo e tem como função de distribuição uma gaussiana (MANTEGNA; STANLEY, 2000). Esse modelo, conhecido como modelo Browniano Geométrico, possui diversas simplificações que permitem a realização de cálculos analíticos. Porém, os dados empíricos das séries de retorno apresentam função de distribuição leptocúrtica. Quanto maior a frequência dos dados, maior é o grau de leptocurtose observado. As caudas gordas típicas dessas distribuições podem ser captadas visualmente na Figura 9.

Uma forma de medir quanto uma determinada distribuição desvia de uma distribuição normal é utilizando a medida de curtose (CONT, 2001):

$$
k=\frac{\left\langle[r(t, \Delta t)-\langle r(t, \Delta t)\rangle]^{4}\right\rangle}{\sigma^{4}}-3
$$

Definida dessa maneira, a curtose para uma distribuição gaussiana é nula, enquanto para distribuições com caudas gordas $\mathrm{k}>0$.

Alguns estudos demonstram que as caudas gordas apresentadas pelas distribuições de retorno têm decaimentos que seguem uma lei de potência com $\alpha \sim 3$, ou até mesmo valores maiores, $3 \leq \alpha \leq 5$ (GOPIKRISHNAN et al., 1999; BOUCHAUD; POTTERS, 2003). Além de apresentarem curtose positiva, as distribuições de retorno de ativos dos mercados financeiros apresentam assimetria. Bouchaud e Potters (2003) mostram que a assimetria é pequena, muito menor que as curtoses observadas, além disso, a assimetria é uma característica muito sensível à quantidade que se toma para estudo, como o incremento absoluto de preços ou o incremento
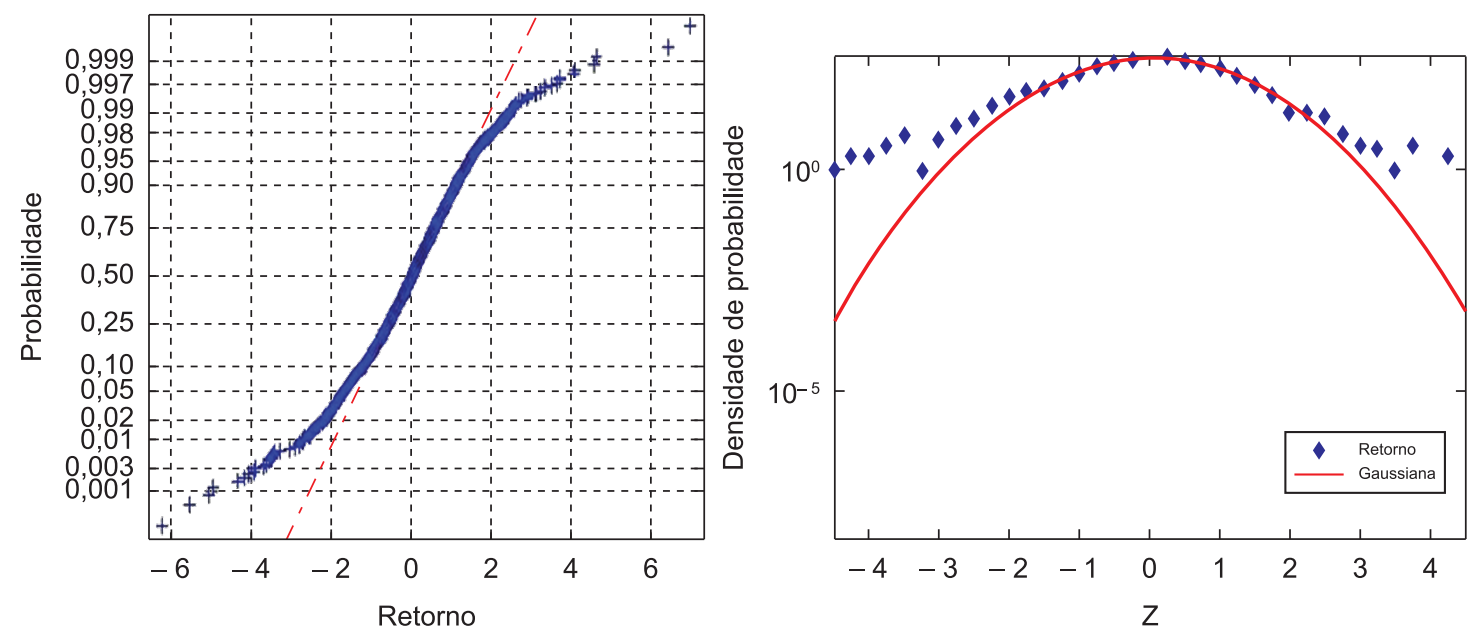

Figura 9. Densidade de probabilidade do retorno comparada com uma gaussiana em duas maneiras diferentes. Em ambas fica evidente que as caudas da distribuição do retorno são mais pronunciadas que aquela apresentada por uma distribuição gaussiana. Valores do Índice Bovespa de jan./2000 a set./2011. 
relativo de preços. Em muitos casos, constata-se que a assimetria é negativa, ou seja, há uma chance um pouco maior de ocorrências de perdas do que ganhos no mercado financeiro (CONT, 2001).

A partir das observações iniciais de Mandelbrot sobre a estabilidade funcional para diferentes escalas de tempo e da ocorrência de caudas gordas, procurou-se estabelecer uma forma funcional que se ajustava aos dados. O próprio Mandelbrot propôs uma distribuição de Levy-estável. Porém esse tipo de distribuição apresenta variância infinita, dificultando a aplicação de modelos.

Comparando os dados de mercado com uma Levy-estável e com uma gaussiana, observa-se que o centro da distribuição é bem ajustado pela Levy-estável, contudo, a cauda da distribuição tem comportamento intermediário entre os ajustes de uma gaussiana e de uma Levy-estável, o que mostra que os dados têm distribuição com variância finita (MANTEGNA; STANLEY, 2000). Como o decaimento da cauda dos dados empíricos é mais lento que uma gaussiana - estando fora, porém, do regime de uma Levy-estável -, surgiu a questão de como a forma funcional se manteria para várias escalas de tempo. Uma possível explicação é que os dados estariam distribuídos segundo uma Levy-truncada, em que as caudas seguem aproximadamente uma exponencial (GOPIKRISHNAN et al., 1999; MANTEGNA;
STANLEY, 2000). Essa resposta garante que a variância tenha valor finito, porém, a Levy-truncada não é uma distribuição estável.

Como os dados empíricos do retorno apresentam distribuição não estável, espera-se que haja uma convergência para uma distribuição gaussiana à medida que os valores sejam tomados com intervalos temporais, $\Delta \mathrm{t}$ cada vez maiores. Essa característica é chamada gaussianidade agregativa e é apresentada na Figura 10.

Um fenômeno que denota a característica de persistência nas séries de retorno são as caudas gordas condicionais. Esse fato estilizado é verificado quando, após filtrar a série original, utilizando, por exemplo, um modelo do tipo GARCH (CONT, 2001), a série resultante ainda exibe caudas gordas, apesar de serem caudas menos pesadas que aquelas obtidas a partir da série original.

Além de se conhecer os detalhes da forma funcional da distribuição do retorno, é interessante verificar o comportamento de correlação dos dados dessa variável. Para esse fim, utiliza-se, com frequência, a função de autocorrelação:

$$
C(t)=\operatorname{corr}(r(t, \Delta t), r(t+\tau, \Delta t))
$$

em que $\mathrm{C}$ é correlação, $\mathrm{r}$ o retorno, $\tau$ o incremento temporal, $\mathrm{t}$ o tempo, $\Delta \mathrm{t}$ o intervalo de tempo entre dados sucessivos da série e corr é a correlação dada por:

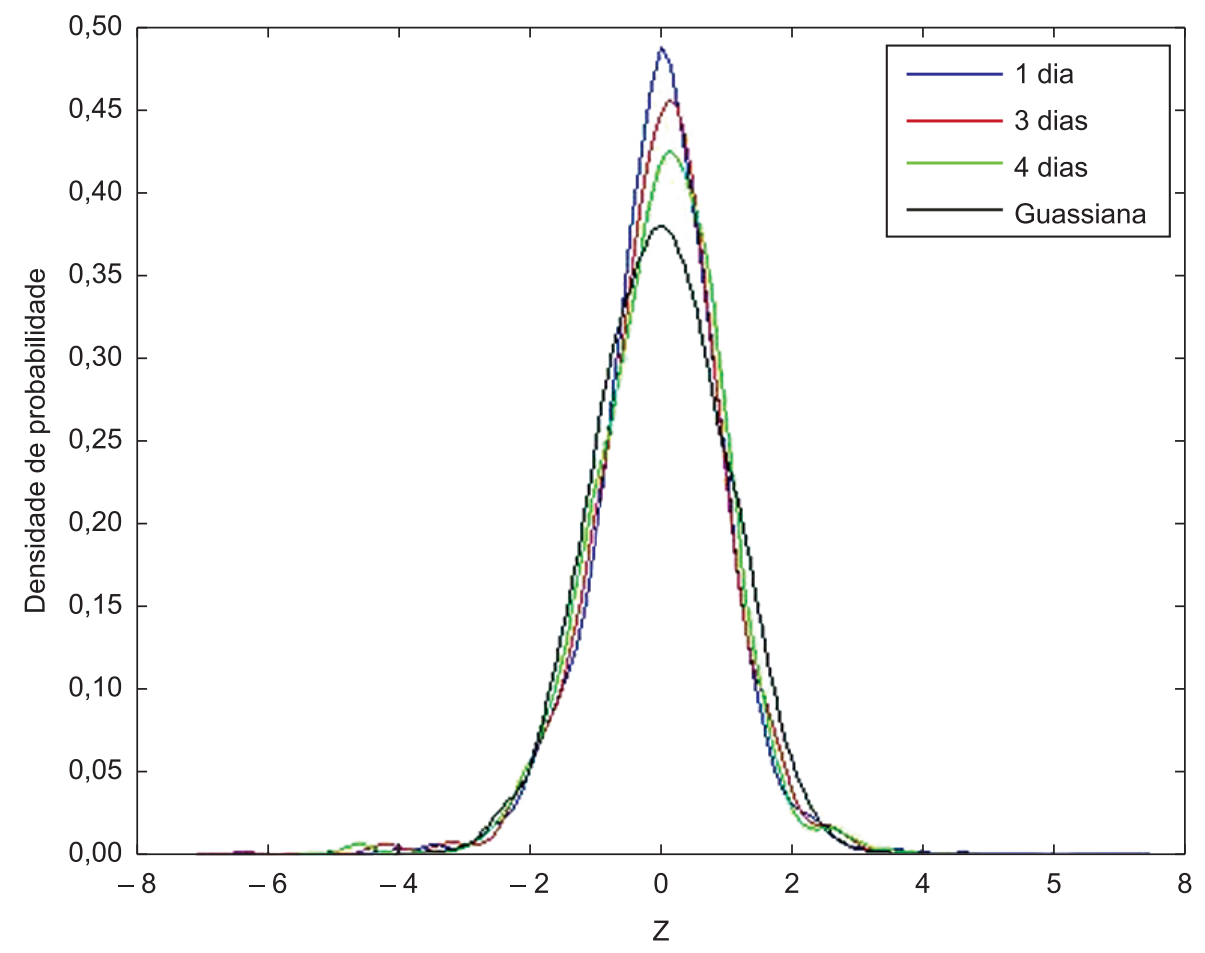

Figura 10. Variação da forma da densidade de probabilidade com o aumento do intervalo temporal de amostragem, evidenciando a gaussianidade agregativa. A variável Z corresponde ao valor normalizado do retorno. Valores do Índice Bovespa de jan./2000 a set./2011. 


$$
\operatorname{corr}(X, Y)=\frac{E[X . Y]-E[X] \cdot E[Y]}{\sigma_{X} \cdot \sigma_{Y}}
$$

Essa função aplicada à variável retorno apresenta tendência rápida para valores próximos de zero (GOPIKRISHNAN et al., 1999; CONT, 2001; MANTEGNA; STANLEY, 2000; BOUCHAUD; POTTERS, 2003; TANG; HUANG, 2000). Esse resultado pode ser observado na Figura 11.
A partir de um resultado que apresenta nível de ruído para a função de autocorrelação - ou seja, considera-se essa medida como nula para a série de retorno -, poderia se suscitar uma interpretação equivocada, uma vez que o resultado nulo corrobora a hipótese de eficiência de mercado (GOPIKRISHNAN et al., 1999), a de que a variável retorno é temporalmente independente. Entretanto, sabe-se que a existência da variável independente implica em autocorrelação

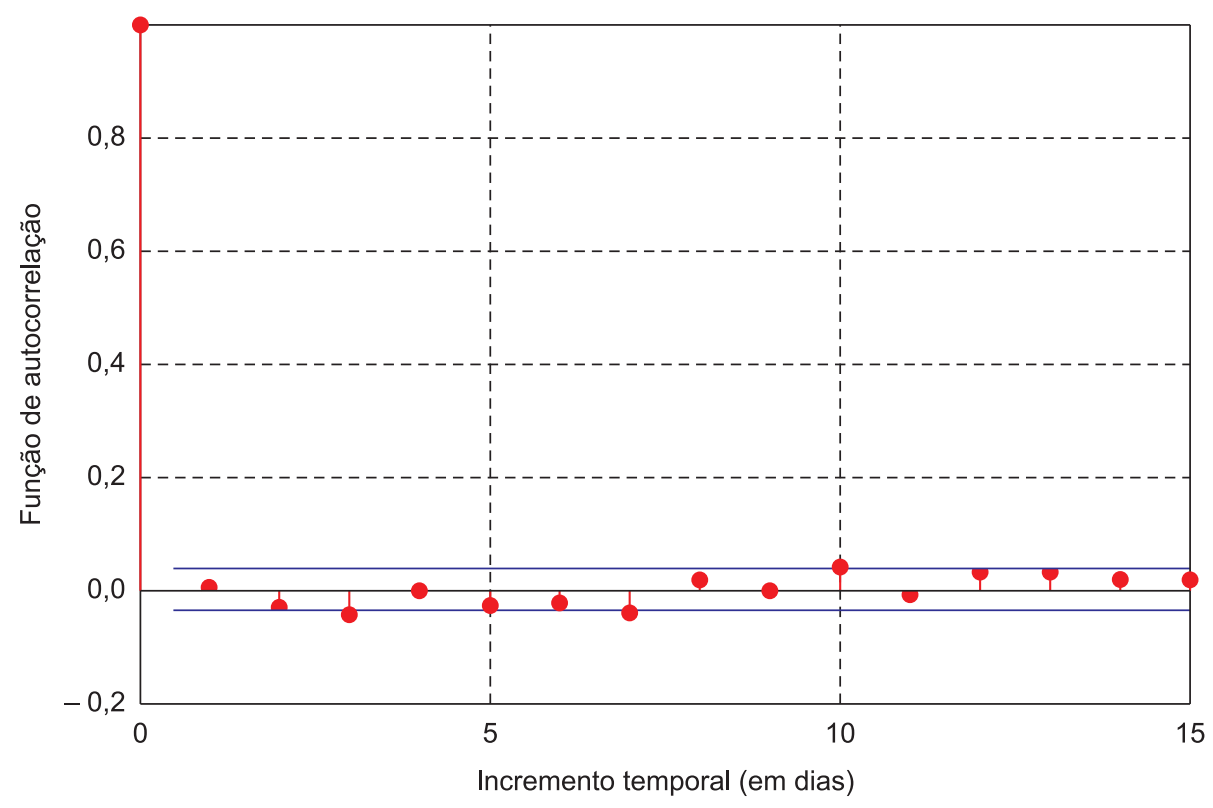

Figura 11. Função de autocorrelação do retorno. Observa-se que todos os valores são aproximadamente nulos, utilizando um nível de confiança de 95\% (retas paralelas ao eixo da abscissa). Valores do Índice Bovespa de jan./2000 a set./2011.

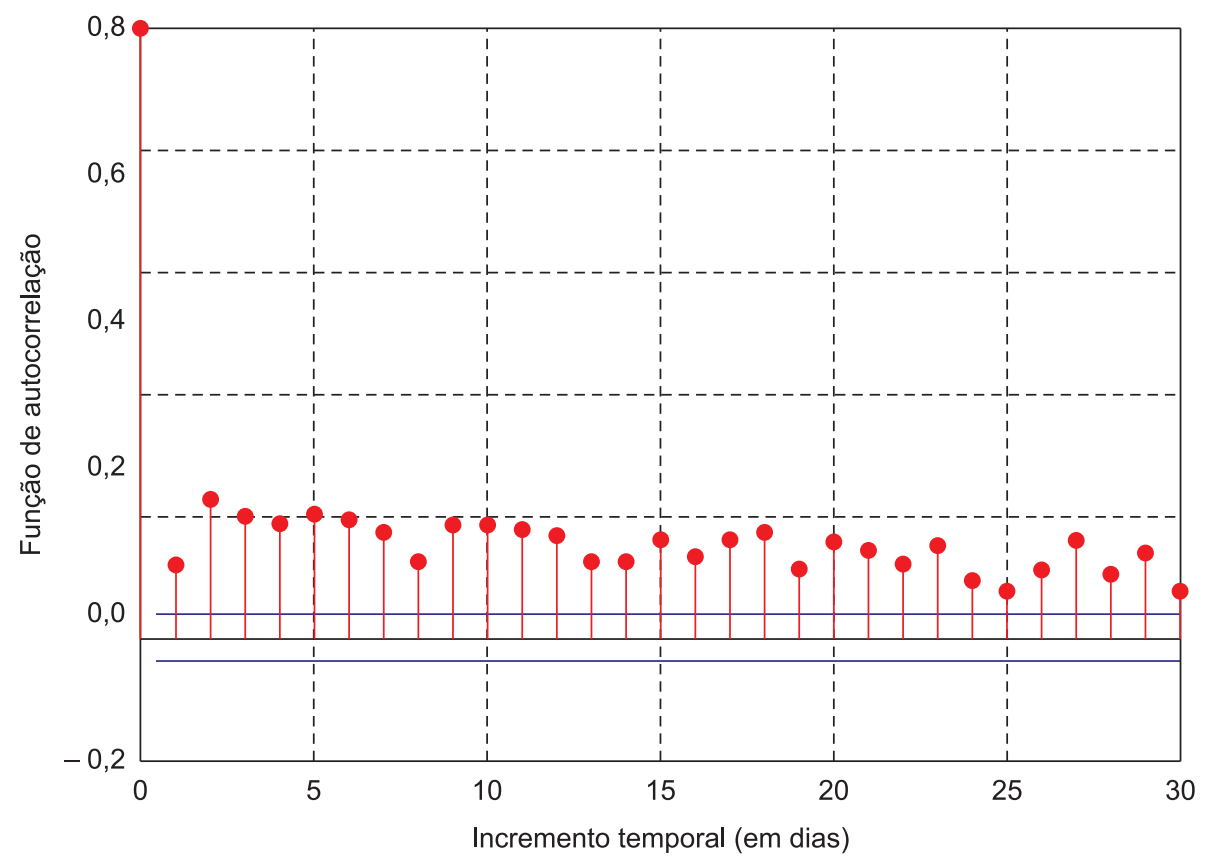

Figura 12. Função de autocorrelação da volatilidade (módulo do retorno). Observa-se o decaimento lento dos valores, utilizando um nível de confiança de 95\% (retas paralelas ao eixo da abscissa). Valores do Índice Bovespa de jan./2000 a set./2011. 
nula, e não o contrário. Caso houvesse independência, ao se calcular a autocorrelação para funções não lineares dos retornos, como o valor absoluto ou o quadrado dos retornos, essa apresentaria medida nula, o que não se verifica (GOPIKRISHNAN et al., 1999; CONT, 2001; BOUCHAUD; POTTERS, 2003). O valor absoluto dos retornos é uma medida de sua intensidade e, muitas vezes, é tomado como forma de cálculo da volatilidade. Desse modo, acaba-se obtendo o fato estilizado denominado decaimento lento da autocorrelação da volatilidade. Ao se calcular a função de autocorrelação da série temporal da volatilidade dos ativos, verifica-se persistência com um decaimento lento (GOPIKRISHNAN et al., 1999; CONT, 2001), como demonstrado na Figura 12.

Existem dois fatos estilizados relacionados às séries de volatilidade, que são constatados visualmente, seja observando a própria série, ou, o que talvez chame

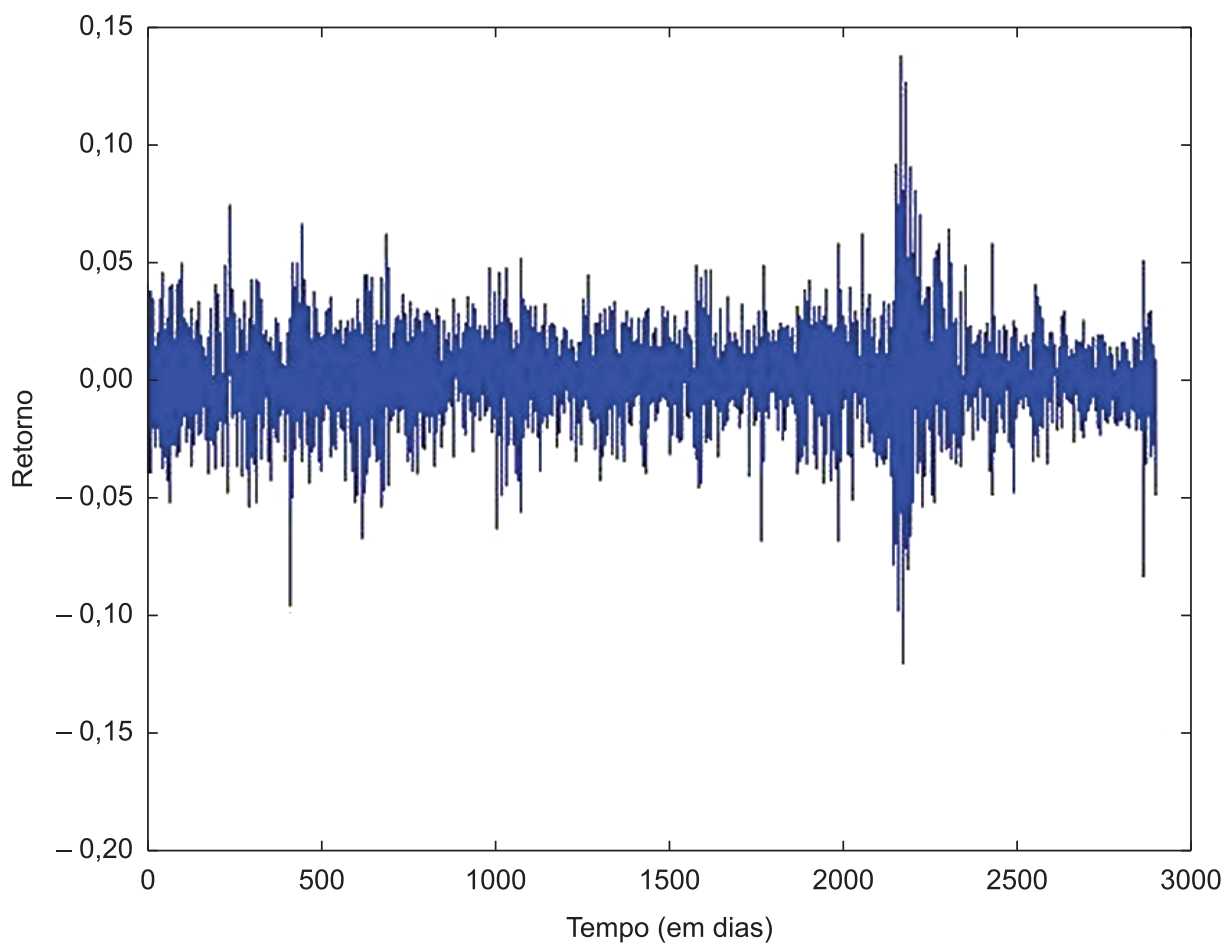

Figura 13. Série temporal do retorno do Índice Bovespa de jan./2000 a set./2011. Verificam-se os aglomerados de volatilidade, em especial o período entre 2000 e 2500 dias, que corresponde à crise do subprime americano.

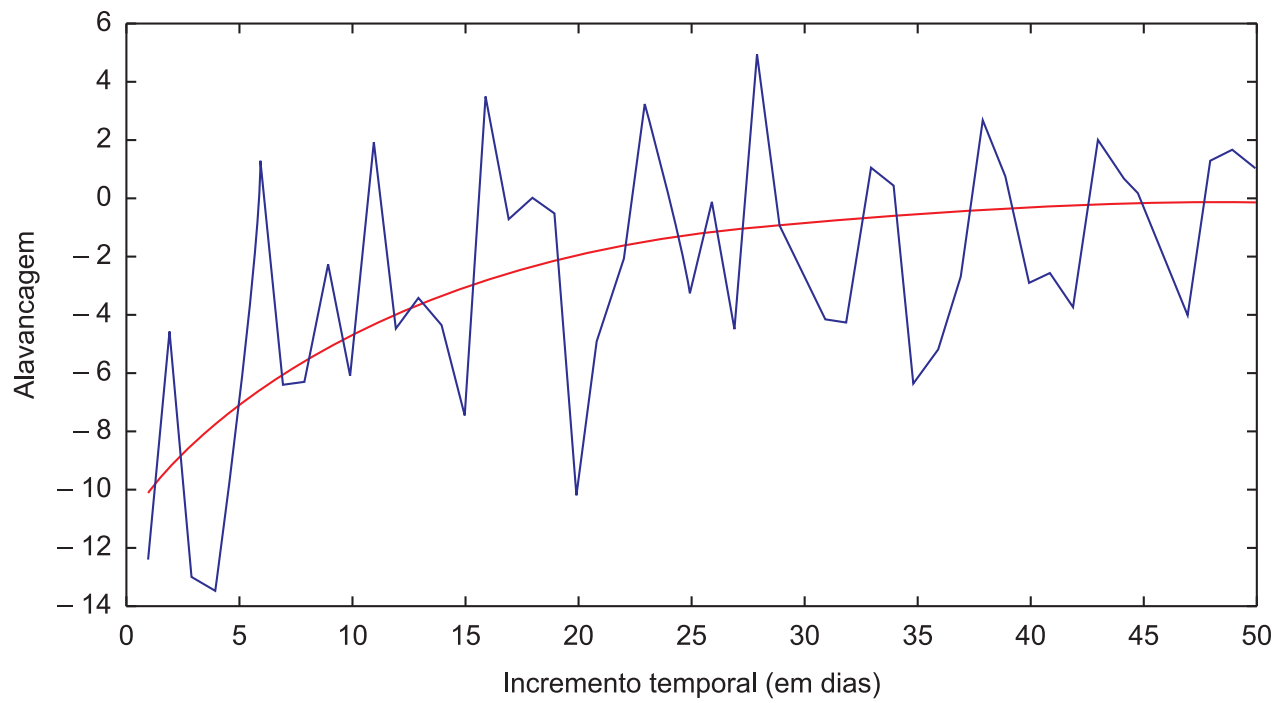

Figura 14. Efeito de alavancagem do Índice Bovespa (jan./2000 a set./2011). Ajuste exponencial com tendência a zero com o aumento do incremento temporal. 
mais a atenção, visualizando o comportamento da série de retorno. São eles a intermitência e o agrupamento de volatilidade (volatility clustering). A intermitência é caracterizada por grandes rupturas na intensidade de variação dos retornos, que acontecem de forma irregular na série temporal, de modo que a alternância entre alta e baixa volatilidade, e vice-versa, não se dá de forma suave, como se houvesse uma resistividade ou efeito inercial. O nome em si, adotado, é uma analogia ao comportamento de fluxos turbulentos em que períodos de relativa tranquilidade são interrompidos por variações intensas no fluxo (BOUCHAUD; POTTERS, 2003). Já o agrupamento de volatilidade reflete o fato de que grandes variações de preços são mais prováveis de serem seguidas por comportamentos de mesma intensidade e vice-versa. Assim, observam-se nas séries de retornos blocos ou agrupamentos temporais com grande intensidade de flutuação do retorno (BOUCHAUD; POTTERS, 2003). Na Figura 13, é possível identificar a intermitência e agrupamentos de volatilidade.
Um último fato estilizado a ser mencionado é o efeito de alavancagem. Ele é o resultado da ocorrência de correlação entre retornos tomados no passado com a volatilidade tomada em tempos posteriores (CONT, 2001):

$$
L(\tau)=\operatorname{corr}\left(r,|r(t+\tau)|^{2}\right)
$$

A correlação existente é negativa e torna-se nula com o aumento de $\tau$, que, no caso, é o deslocamento temporal da variável retorno ao quadrado, de tal forma que a interpretação válida é que: alterações atuais do retorno estão correlacionadas negativamente com alterações futuras da volatilidade, ou seja, períodos de alta volatilidade são precedidos por variações negativas do retorno e vice-versa. Porém não se constata o efeito de alavancagem no sentido inverso. É insignificante a correlação quando se toma um valor de $\tau$ negativo, de tal maneira que a interpretação cabível seria que alterações do retorno fossem precedidas por mudanças na volatilidade, portanto $\mathrm{L}(\tau) \neq \mathrm{L}(-\tau)(\mathrm{CONT}, 2001)$. A Figura 14 demonstra o efeito de alavancagem. 
